OPEN ACCESS

Edited by:

Xiangyu Wang,

Curtin University, Australia

Reviewed by:

Daejin Kim,

lowa State University, United States

Andreas Ihle,

Université de Genève, Switzerland

*Correspondence:

Sung J. Park

sjpark@kmu.ac.kr

Specialty section:

This article was submitted to

Environmental Psychology,

a section of the journal

Frontiers in Psychology

Received: 13 October 2019

Accepted: 03 January 2020

Published: 11 February 2020

Citation:

Lee EJ and Park SJ (2020) Immersive Experience Model of the Elderly Welfare Centers Supporting

Successful Aging.

Front. Psychol. 11:8.

doi: 10.3389/fpsyg.2020.00008

\section{Immersive Experience Model of the Elderly Welfare Centers Supporting Successful Aging}

\author{
Eun J. Lee ${ }^{1}$ and Sung J. Park ${ }^{2 *}$ \\ ${ }^{1}$ Department of Architecture, Keimyung University, Daegu, South Korea, ${ }^{2}$ Department of Architectural Engineering, \\ Keimyung University, Daegu, South Korea
}

This study investigates the application of immersive experience services to leisure facilities for the successful aging of the elderly. In the past, the social image of the elderly was that of passive beings who needed care due to physical and cognitive decline associated with biological aging. However, the concept of "successful aging" actively highlighting the positive aspects of aging and trying to promote longer and healthier life has started to acquire importance in recent years. In this context, elderly welfare centers can be described as facilities that encourage learning, leisure, and social activities of the elderly with impaired physical and cognitive functions. The use of recent immersive experience technologies such as virtual reality and mixed reality (MR), in order to mitigate physical and spatial constraints and provide an immersion into the desired environment and situation, could contribute substantially to the health of the elderly. However, the application of immersive technologies is concentrated on the provision of entertainment, education, and medical facilities. The number of previous studies on the immersion experiences of the elderly is limited, and the connection between immersion experiences and various services and programs that promote successful aging at elderly welfare centers requires further research. This study analyzes the function and space of the elderly welfare centers for successful aging through the review of previous studies and classifies immersion technology categories based on the review of the relevant literature. The study analyzes the health benefits of immersive experience technologies and related products and services and proposes an immersive experience service model for the elderly welfare center. The results of the study could provide a valuable input for the spatial application of immersive experience technologies for successful aging in the future.

\section{Keywords: successful aging, elderly welfare center, the elderly, immersive experience, immersive experience service, immersive technology}

\section{INTRODUCTION}

The rapid growth of the elderly population is a global trend. Korea has become an aged society in 2017, after only 17 years as an aging society. The proportion of people aged 65 or older currently exceeds 15 percent, with the elderly population expected to reach 10 million people by 2026, making Korea a post-aged society (Statistics Korea, 2018). Korea’s entry rate to aging society is considerably 
faster than in other developed countries such as the United States (73 years), Germany (40 years), and Japan (24 years) (OECD, 2005). Population aging is generally perceived as an increase in older (over 65) dependent populations that need to be cared for financially and medically in terms of national and social aspects. However, with the continued improvement of the educational and economic levels of the elderly, there is a growing interest in "successful aging," a term which highlights the positive aspects of aging and involves a longer and more active life. Successful aging is the process of proactively coping with the fear of inevitable declines associated with an old age; this is done by maintaining high levels of physical, mental, and social activity and acting as an active rather than passive member of society. This new perception of aging requires a new paradigm different from the existing focus on the medical and welfare systems.

Recent studies suggest that "immersion experience" technology using information and communication technology (ICT) and virtual reality (VR) can promote the health and well-being of the elderly (Yamagami et al., 2007; Angelini et al., 2015). Immersive experience can contribute significantly to successful aging by inducing positive experience and facilitating communication of the user through a new or familiar virtual content. However, the existing immersion technology applications are largely provided for the purpose of entertainment, education, or therapy. They have limited application measures to the housing and hospital used to house and care of the elderly. The elderly welfare centers that provide leisure activities, disease prevention, and social interaction need to find ways to also provide these and other cost-effective services from the perspective of successful aging.

The purpose of this study is to develop the immersive experience service model that can be applied at the elderly welfare centers via linking the main functions of the elderly welfare center for successful aging with the immersive experience technology that can support it. This study analyzes the possibility of the positive immersive experience for the elderly and suggests an interaction and application method based on the programs supported by the elderly welfare centers as well as spatial needs. The immersive experience service model developed here suggests new developments in the field of immersive experience content and healthcare services.

\section{RESEARCH SCOPE AND METHODOLOGY}

Several research steps have been taken in this study (Figure 1). Firstly, the concept of successful aging and the characteristics of immersive experience were analyzed through literature review. Secondly, the study analyzed the function and program space at the elderly welfare centers from the perspective of successful aging and reviewed the literature focused on identifying the positive effects of immersive technology for the elderly. Here, we analyzed the immersive experience technology and related products and services for the elderly. The literature reviewed included journal articles, extended abstracts, and conference proceedings, using databases such as ScienceDirect, ERIC,
SpringerLink, and EMBASE. Three search keywords were used: "elderly," "immersive technology," and "immersive experience."

Thirdly, we derived service contents and related immersion skills based on the characteristics of the immersion experience and the function of the elderly welfare center. Fourthly, the immersive experience service composition system and a service platform were established, and the contents of the immersive experience service-based service platform were derived based on the functions of the elderly welfare centers. And finally, an immersive experience service model is proposed, taking into account the spatial function of the elderly welfare centers.

\section{SUCCESSFUL AGING AND IMMERSIVE EXPERIENCE}

\section{Successful Aging}

"Aging" is a progressive degeneration process that is accompanied by a decline in biological function and an increase in mortality with age (Hayflick, 2000). With the development of medical technology and educational level, elderly health care has begun to focus on understanding not only biological aging but also social and psychological aging and on seeking ways to support the multidimensional needs and requirements of the elderly. In particular, as social myths about aging gradually shift from negative to positive, "successful aging" has emerged as the subject of neo-aging and has been studied in various definitions and measures over the past decades (Rowe and Kahn, 1998; Nusselder and Peeters, 2006; Ouwehand et al., 2007; Chodzko-Zajko et al., 2009). A theory of successful aging has been established to describe conditions meeting social and biomedical needs of the elderly. The former includes satisfaction with life, psychological well-being, social functioning, and so forth, whereas the latter emphasizes physical and cognitive functionality. Havighurst (1963) defined successful aging as social adaptation from a social psychology perspective, stating its importance for social stability and the flexibility of personality and relationships in this process. On a social side, successful aging implies that emotional attachment and self-esteem stem from personal experiences and memories, controllable circumstances, or circumstances not necessarily influenced by environmental characteristics (Baltes and Baltes, 1990) and that the relaxation of mind through involvement with nature is one of the main factors of being happy in old age (Bhatt, 2015). Successful aging on the biomedical side, on the other hand, implies minimizing the physiological degradation and increasing active life expectations through the prevention of chronic diseases (Chodzko-Zajko et al., 2009). Other successful aging factors include longevity, active (healthy) life, disease-free life, absence of chronic disease, reduced depression and loneliness, and high physical and mental functionality (Nusselder and Peeters, 2006; Ouwehand et al., 2007).

In contrast, Rowe and Kahn (1998) noted that aging should be considered in a variety of ways, rather than in one aspect. This can be explained by distinguishing between the usual aging and successful aging. Usual aging refers to helpless old age with no specific disease or dysfunction, but with risk factors 


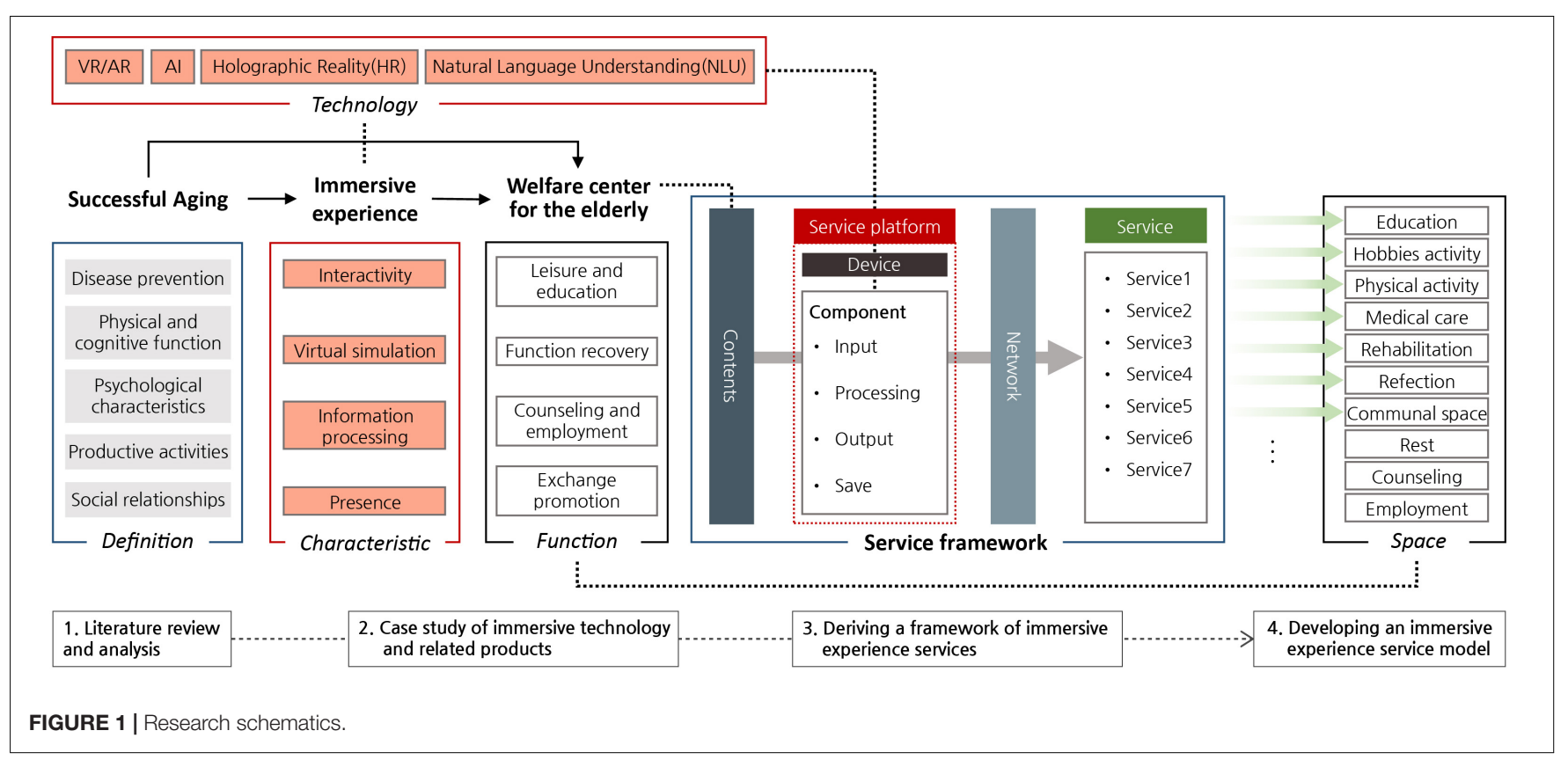

for disease, while successful aging can overcome or delay the universal aging with appropriate control of the environment and individual efforts. Thus, aging may be different depending on the environment or individual ability; therefore, supportability should be considered in individual and diversified aspects.

Recent studies have categorized the concept of successful aging into five different areas, namely, disease prevention and health, physical and cognitive functioning, psychological characteristics, social relations, and productive activities (Rowe and Kahn, 2015). Learning is often emphasized as a successful aging factor (Duay and Bryan, 2006), and research shows that participation in educational and creative activities in old age can have a positive impact on aging (Gallistl, 2018). The purpose of this study is to support successful aging in the five categories listed above. These are described below in more detail (Table 1).

Disease prevention is the prevention of risk factors for diseases and disorders. Preventive support is particularly important for older people because they may experience chronic or non-specific

TABLE 1 | Definition of successful aging.

\begin{tabular}{ll}
\hline Successful aging & Definition \\
\hline Disease prevention & $\begin{array}{l}\text { Prevention of disease-related hazards, knowledge of } \\
\text { health, and awareness of one's health condition }\end{array}$ \\
$\begin{array}{l}\text { Physical and } \\
\text { cognitive function } \\
\text { and short-term memory, proper exercise, and physical } \\
\text { fitness training }\end{array}$ \\
$\begin{array}{l}\text { Psychological } \\
\text { characteristics }\end{array}$ & $\begin{array}{l}\text { Emotional stability, attachment to experiences and } \\
\text { memories, absence of depression and loneliness, high }\end{array}$ \\
Productive activities & $\begin{array}{l}\text { Continuing educational and self-development, motivation } \\
\text { for life, social activities, and an active attitude to learning } \\
\text { Close relationships with others, forming social bonds, } \\
\text { adaptability to the environment, and social support }\end{array}$
\end{tabular}

illnesses including multiple medically unexplained symptoms (MMUS). Physical and cognitive functioning describes the potential for the elderly people to live independently and is also a prerequisite for successful aging. The psychological characteristics involve acknowledging aging and embracing various aspects of one's life, looking forward to life, and finding a meaning. Productive activities include a positive view of knowledge and skills and, in particular, educational activities that, along with self-development, can be a motivation for a new life goal (Vaillant, 2008). Finally, maintaining social relationships with others is related to the adaptability to the environment and provides an opportunity for an improved well-being. In other words, successful aging should strive to expand the individual's capacity and help maintain better functions, as well as to support active relationships and participation in productive roles rather than adapting to the existing society.

\section{Characteristics of Immersive Experience}

Recent advances in media technology have resulted in the development of the new display and communication devices that can simulate environments which are very similar to reality or simulate a complete virtual reality (Jeong, 2019). The user can then maximize their presence and immersion in the displayed environment and experience a natural and intuitive interaction with the $3 \mathrm{D}$ structure. The result is an immersive user experience and improved interaction technologies that provide an opportunity to better serve the elderly who are vulnerable to the information society and digital devices. The ultracompact devices or smart devices that are required in modern society cannot meet the physical, cognitive, and emotional needs of the elderly due to the small displays and the need for continuous operation. Immersive technology supports $3 \mathrm{D}$ virtual content and natural communication and helps to improve social interactions and physical functions by allowing the user to be 
TABLE 2 | Characteristics of immersive experience and technology (based on study by Jeong, 2019).

\begin{tabular}{|c|c|}
\hline $\begin{array}{l}\text { Characteristics } \\
\text { of immersive } \\
\text { experience }\end{array}$ & Contents \\
\hline Interactivity & $\begin{array}{l}\text { - Users can quickly and easily select the information they } \\
\text { want and can control or adjust the situation based on } \\
\text { the information they choose }\end{array}$ \\
\hline \multirow[t]{2}{*}{ Virtual simulation } & $\begin{array}{l}\text { - Users can reproduce or manipulate things that are not } \\
\text { directly experienced within a complete virtual space } \\
\text { - Users can communicate through an "avatar" with other } \\
\text { participants in the virtual space }\end{array}$ \\
\hline & $\begin{array}{l}\text { - Various sensory sensors can acquire and transmit } \\
\text { information about the user }\end{array}$ \\
\hline $\begin{array}{l}\text { Information } \\
\text { processing }\end{array}$ & $\begin{array}{l}\text { - A kind of sensory immersion, awareness of the user's } \\
\text { biological signals and behaviors, and automated service } \\
\text { delivery }\end{array}$ \\
\hline Presence & $\begin{array}{l}\text { - Users can experience mixed reality (MR) and realistic } \\
\text { media in realistic three-dimensional and vivid expression } \\
\text { - Includes super-high-definition display and holograms, } \\
\text { audio system, etc. }\end{array}$ \\
\hline
\end{tabular}

immersed in the desired environment (Whitlock et al., 2012; Wiemeyer and Kliem, 2012; Wu et al., 2013).

Immersion means lifelike vividness of the user surroundings and provides various immersion experiences by maximizing reality and minimizing physical constraints. The immersive experience can display characteristics such as interactivity, virtual simulation, information processing, and virtual presence. The details of the immersion experience characteristics are shown in Table 2 (Jeong, 2019).

Immersive experience promotes user-centered information transfer and exchange while leading to satisfactory results by allowing interaction with the environment as an active agent (Sauter, 2003). In other words, it satisfies the desire for empathy going beyond the sensory stimulation of the individual and has a positive effect on cooperativeness and social exchange. As a result, immersive experience has the potential to become a tool for achieving a physical, emotional, and social satisfaction. Based on all of this, it is essential to discuss the use of immersive experience in the context of health and welfare services provision.

\section{ELDERLY WELFARE CENTERS AND IMMERSIVE TECHNOLOGY}

\section{Elderly Welfare Center Supporting Successful Aging}

The elderly welfare centers in Korea are leisure facilities for the elderly, providing leisure activities, health care, and social activities for the elderly. They are similar to the elderly welfare centers in Japan and the multipurpose senior centers in the United States, as well as Altentagesstätta in Germany (Lim et al., 2014). The goal of the elderly welfare centers is to provide a comprehensive service for the elderly in different communities, for them to be able to live comfortable and independent lives (Park et al., 2013). To this end, the Elderly Welfare Act proposes operating and facility standards for these centers through the
Elderly Welfare Center Enforcement Rules. The operation of the elderly welfare centers is defined as a provision of life and health counseling for the elderly, provision of employment information, rehabilitation or functional reinforcement training, and provision of programs to improve education including liberal arts. Additional detailed programs and services should be planned, taking into account the characteristics of each community and audience.

The elderly welfare centers are a community-oriented elderly welfare service network supporting the creation of local communities and the multidimensional welfare of the elderly following the current direction of elderly welfare practice which agrees with the "aging in place" (AIP) concept. AIP is a strategy for successful and active aging, meaning aging with people who are familiar in familiar areas. However, this strategy is also used in the expectation that community care is costeffective in mitigating financial burdens (Vasunilashorn et al., 2012). Accordingly, this study found similarities between the direction of successful aging and the ultimate goal of the elderly welfare centers. The functions of the elderly welfare centers were categorized into leisure and education, function recovery, counseling and employment, and social interaction promotion functions.

An elderly welfare center usually has a floor area of $500 \mathrm{~m}^{2}$ or more and at least one essential facility such as an auditorium, an office, a counselor office, a restaurant, or a program room. As of 2018, there were 385 elderly welfare centers in Korea, with an average total floor area of $2,500 \mathrm{~m}^{2}$, which is about three times larger than that in Japan (Ministry of Health and Welfare, 2019). Compared to other elderly leisure welfare facilities, the ratio is high in scope, number, and number of users. However, since the 2011 amendment to the Elderly Welfare Act, there have been no significant changes in the provision of the programs in these centers (Hong and Yoo, 2017).

This study derives spatial composition based on the function of elderly welfare centers for successful aging (Park et al., 2013; Shin, 2016; Hong and Yoo, 2017; Kim et al., 2017). Table 3 summarizes the association between the function of an elderly welfare center and successful aging. Depending on the function, an elderly welfare center can consist of up to 10 spaces for hobbies, physical activities, education, medical care, rehabilitation, counseling and employment, refection, and rest. Each space is classified into a detailed set of functions, based on the intended program of use. Based on the analysis of the spaces related to successful aging, we found an association between disease prevention (5), physical and cognitive functions (7), psychological characteristics (4), and productive activities (3) and social relationships (5).

\section{Immersive Experience Technology for the Elderly}

A recent innovative immersion technology implementation included sophisticated computer graphic technology, network technology for massive data transmission, and a humancentered interaction solution that delivers five senses (Cummings and Bailenson, 2016). Immersion technology 
TABLE 3 | Functions and space composition of the elderly welfare center for successful aging.

\begin{tabular}{|c|c|c|c|c|c|c|c|}
\hline \multicolumn{3}{|c|}{ Welfare facility for the elderly } & \multicolumn{5}{|c|}{ Successful aging } \\
\hline Function & \multicolumn{2}{|r|}{ Space } & \multirow[t]{2}{*}{$\begin{array}{c}\text { Disease } \\
\text { prevention }\end{array}$} & $\begin{array}{c}\text { Physical and } \\
\text { cognitive } \\
\text { function }\end{array}$ & $\begin{array}{l}\text { Psychological } \\
\text { characteristics }\end{array}$ & $\begin{array}{l}\text { Productive } \\
\text { activities }\end{array}$ & $\begin{array}{l}\text { Social } \\
\text { relationships }\end{array}$ \\
\hline \multirow[t]{3}{*}{$\begin{array}{l}\text { Leisure and } \\
\text { education }\end{array}$} & Hobbies activity & $\begin{array}{l}\text { Multipurpose room, auditorium, hobby } \\
\text { classroom, arcade/game room, art gallery }\end{array}$ & & $\bullet$ & & $\bullet$ & $\bullet$ \\
\hline & Physical activity & Weight room, yoga/aerobics room, sports room & $\bullet$ & $\bullet$ & & & \\
\hline & Education & Classroom, computer room, library, assembly hall & & $\bullet$ & & $\bullet$ & \\
\hline \multirow[t]{2}{*}{$\begin{array}{l}\text { Function } \\
\text { recovery }\end{array}$} & Medical care & $\begin{array}{l}\text { Examining room, physiotherapy room, Chinese } \\
\text { medical treatment room }\end{array}$ & $\bullet$ & $\bullet$ & $\bullet$ & & \\
\hline & Rehabilitation & $\begin{array}{l}\text { Movement training room, rehabilitation room, } \\
\text { meditation room, recovery room }\end{array}$ & $\bullet$ & $\bullet$ & $\bullet$ & & \\
\hline \multirow[t]{2}{*}{$\begin{array}{l}\text { Counseling and } \\
\text { employment }\end{array}$} & Counseling & $\begin{array}{l}\text { Health counseling and guidance room, } \\
\text { psychology consultation room }\end{array}$ & $\bullet$ & $\bullet$ & $\bullet$ & & $\bullet$ \\
\hline & Employment & $\begin{array}{l}\text { Employment consultation room, employment } \\
\text { information room }\end{array}$ & & & & $\bullet$ & \\
\hline \multirow{3}{*}{$\begin{array}{l}\text { Exchange } \\
\text { promotion }\end{array}$} & Refection & Restaurant, kitchen, cafeteria & & & & & $\bullet$ \\
\hline & Rest & Indoor garden, lounge & & & $\bullet$ & & $\bullet$ \\
\hline & $\begin{array}{l}\text { Communal } \\
\text { space }\end{array}$ & Entrance, stair hall, corridor, lobby & & $\bullet$ & & & $\bullet$ \\
\hline
\end{tabular}

"•" means there is a connection between rows and columns.

is a computer-based device to improve user attention and concentration, in both physical and cognitive respects. It is made by combining technologies from various fields (Keshner and Kenyon, 2004). More specifically, immersive experience technology includes technologies supporting multimodal interaction to immerse the user in a virtual platform which is the result of a computer combined with the real physical environment. This study analyzed the characteristics of the immersive experiment and contents related to immersion technology through advanced research on technology for the elderly (Table 4). Previous studies focused on analyzing the elderly's interaction with virtual information and objects or techniques for immersing in information and content provided. Experimental studies related to the immersion experience of the elderly mainly focus on the contents of the Internet and smartphone use. There is insufficient empirical research on the immersion technology utilization and immersion experience. Immersion technology and immersion experience for the elderly can be classified into interactive video game-based (IVGB) games, robots based on artificial intelligence (AI) or natural language understanding (NLU), and immersive content using augmented and mixed reality. The results of previous studies show that immersion experiences are related to physical, mental, and social functions of the elderly, especially the IVGB training games that improve sensory and motor skills, perception, and cognition (Whitlock et al., 2012; Lai et al., 2013) and form relationships with the grandchildren (Wollersheim et al., 2010). The AI robots used for social care promote social exchange and emotional relaxation (Libin and Cohen-Mansfield, 2004; Wada and Shibata, 2006), and the use of immersive content can enhance life satisfaction and family bonds (Cornejo et al., 2013).
However, the results of our analysis results indicate that research on immersion technology for the elderly is immature and is mostly based on experiments focused on the Internet and smartphone usage. It is important that immersion technology induces interaction with virtual reality, virtual information, and virtual objects and that it functions to immerse the user in the information or content provided.

Hence, we can say that there is a need for the adoption of major new technologies such as visual reality (VR), augmented reality (AR), AI, NLU, and holographic reality (HR), in order to enhance the immersive experience for the elderly.

Recently, the immersive experience services have been successful at providing products and services in various fields, such as entertainment, education, and medical care. Moreover, with the advancement of major technologies, these are also being used in a more complex manner. This study investigated trends in immersive technology-based products and services that support successful aging. Priority was given to the immersive technologybased products where the customer base or target audience was elderly or where the product and service objectives could function for successful aging. The specific case analysis referred to the information provided by the official homepage of the product and service provider, based on the fact that the official homepage is the best medium to provide clear and detailed information on the relevant product. The products and services based on immersive experience technology for the elderly are presented in Table $\mathbf{5}$.

Virtual reality and AR technologies focus on health benefits that could be achieved through the provision of an immersive positive experience with nature. Examples include a lamp to project virtual sunshine designed by Leslie Nooteboom, a design engineer in England, and an artificial skylight to provide the 
TABLE 4 | Summary of previous studies on immersive experience for the elderly.

Author (year) Participants/users Immersive technology Methods
Outcomes
Interrelationship

Phys. Psych. Soc.

\begin{tabular}{|c|c|}
\hline Lai et al., 2013 & $\begin{array}{l}30 \text { elderly people } \\
\text { over } 65 \text { years of }\end{array}$ \\
\hline $\begin{array}{l}\text { Whitlock et al., } \\
2012\end{array}$ & $\begin{array}{l}39 \text { elderly aged } \\
66-77\end{array}$ \\
\hline
\end{tabular}

Whitlock et al., 39 elderly aged

Wollersheim Older adult women

2013 aged 20-79

Banks et al., 2008 et al., $2010 \quad(n=11)$

Anguera et al., 174 participants
38 elderly people living in long-term facilities
Interactive video game-based (IVGB) physical training using the Xavix measured step system (XMSS)

Conduct performance assessments of the multiplayer online WoW (War of Warcraft) game for cognitive training. In WoW, players complete quests in a persistent virtual world to receive rewards and gain levels, many of which require collaboration and social interaction with other players

Wii games played included table tennis, golf, bowling, sword fighting, archery, boxing, frisbee, tennis and cycling. Standard devices were used such as Wii software, television screen, etc.

NeuroRacer is a game developed to train multi-tasking skills during driving. The game is driving in virtual reality and includes step-by-step training content that must perform various quests

Sony's Aibo is a dog-shaped robot that includes actuators, camera and touch sensors, and stereo sound. Aibo is mobile and autonomous. It can find its power supply by itself and it is programmed to play and interact with humans

Lera et al., 2014
Five elderly people aged $59,63,85,86$, and 90 .
Berg balance scale (BBS), timed up and go (TUG), modified falls efficacy scale (MFES) were measured before and after IVGB training Used the SPPB (Shipley institute of living scale) to perform spatial visualization measurements, perceptual rate measurements, inference ability and memory tests

Users played Nintendo Wii Sport game twice a week for a 6-week period. Full body movements were measured using accelerometers, and psychosocial effects were assessed through end-of-study focus group meetings

Using a stepwise algorithm, the participants individually set the level of difficulty in the game. The criterion for improving multitasking ability is limited to the settlement being improved by more than $80 \%$ in the same quest

Experiments were divided into three groups: uncontrolled group A, group B that lived with Aibo, group $C$ that lived with live pet dog. Groups B and C lived for 8 weeks, 30 min a week with Aibo or a pet dog, and during the experiments, all groups received the UCLA depression scale

A small number of the elderly were tested and then questioned on their acceptability and subjective feelings for MYRAbots (Likert 5-point scale)
Improvement in all results based on the measurements of BBS, TUG and MFES, compared to the results before the IVGB training

Following the WoW game, participants' cognitive abilities appeared to improve. No relationship was found between the age and cognitive change. Lower-ability elderly stood to benefit more from cognitive training

Participants' athletic level has been improved, through easy to learn Wii games. Many of the women noted that playing the games allowed them to feel more connected to their grandchildren. Overall, the results revealed that the participants perceived an improved sense of physical, social and psychological well-being

After a month of training, the results showed significant improvements in the multitasking abilities of the elderly and, in the best case, the participants reached the same level as the one they had in their 20s

Groups B and C were much less lonely than group $\mathrm{A}$, and overall social satisfaction improved. No difference in results was found between having a real pet dog and Aibo

Overall satisfaction with social intimacy and enjoyment averaged 4.73 , a very high average. In addition, the lower the age, the higher was the satisfaction score for usefulness and functionality cameras, speakers, communications systems, etc. The main purpose is to provide information about the time and dosage medicine intake (MYRAbot) to make it easy to use medical drug dispensers. MYRAbot communicates with

(n)


TABLE 4 | Continued

\begin{tabular}{|c|c|c|c|c|c|c|c|}
\hline \multirow[t]{2}{*}{ Author (year) } & \multirow[t]{2}{*}{ Participants/users } & \multirow[t]{2}{*}{ Immersive technology } & \multirow[t]{2}{*}{ Methods } & \multirow[t]{2}{*}{ Outcomes } & \multicolumn{3}{|c|}{ Interrelationship } \\
\hline & & & & & Phys. & Psych. & Soc. \\
\hline $\begin{array}{l}\text { Wada and } \\
\text { Shibata, } 2006\end{array}$ & $\begin{array}{l}12 \text { elderly aged } \\
67-89 \text { in care house }\end{array}$ & $\begin{array}{l}\text { Paro is a seal-shaped robot } \\
\text { with the major senses such as } \\
\mathrm{Al} \text { and NUL based vision, } \\
\text { hearing and balance. Paro } \\
\text { interacts with users through } \\
\text { speech and behavioral pattern } \\
\text { recognition, and can express } \\
\text { emotions according to the } \\
\text { situation }\end{array}$ & $\begin{array}{l}\text { Participants communicated } \\
\text { freely with Paro at the desired } \\
\text { time from morning to afternoon } \\
\text { for about } 2 \text { months. POMS } \\
\text { indicators and urine tests were } \\
\text { conducted to measure } \\
\text { participants' emotional and } \\
\text { physiological responses }\end{array}$ & $\begin{array}{l}\text { The results showed that Paro } \\
\text { encouraged communication, } \\
\text { strengthened social bonds, and } \\
\text { had a significant effect on } \\
\text { emotional stability. In particular, } \\
\text { the urine tests showed positive } \\
\text { changes in hormone levels } \\
\text { associated with physiological } \\
\text { responses }\end{array}$ & $\bullet$ & $\bullet$ & $\bullet$ \\
\hline $\begin{array}{l}\text { Libin and } \\
\text { Cohen-Mansfield, } \\
2004\end{array}$ & $\begin{array}{l}\text { Nine elderly people } \\
\text { aged 83-98 at the } \\
\text { dementia center }\end{array}$ & $\begin{array}{l}\text { NeCoRo, a cat with synthetic } \\
\text { fur, can recognize human } \\
\text { behavior and the environment } \\
\text { through internal sensors of } \\
\text { tactile, sound, visual and } \\
\text { direction. Using } 15 \text { actuators } \\
\text { inside the body, actions are } \\
\text { created according to internal } \\
\text { emotions }\end{array}$ & $\begin{array}{l}\text { Participants communicated } \\
\text { freely with NeCoRo for about } \\
30 \text { min, and indicators such as } \\
\text { ABMI, LMBS, and AAID were } \\
\text { utilized to measure cognitive } \\
\text { function and behavioral } \\
\text { disorder levels. }\end{array}$ & $\begin{array}{l}\text { The results showed that the } \\
\text { more severe the symptoms of } \\
\text { dementia, the lower the level of } \\
\text { interaction. However, the } \\
\text { participants' physically disruptive } \\
\text { behavior and overall agitation } \\
\text { decreased significantly, and they } \\
\text { felt happier following the } \\
\text { interaction with the cat }\end{array}$ & $\bullet$ & $\bullet$ & \\
\hline $\begin{array}{l}\text { Cornejo et al., } \\
2013\end{array}$ & $\begin{array}{l}\text { Two extended } \\
\text { families, including an } \\
\text { elderly person who } \\
\text { has never used a } \\
\text { computer or a } \\
\text { smartphone }\end{array}$ & $\begin{array}{l}\text { Tlatoque is a digital frame that } \\
\text { provides a means to } \\
\text { communicate with Facebook to } \\
\text { exchange images and other } \\
\text { information collected by users } \\
\text { in their homes. That is, it is a } \\
\text { ubiquitous system that moves } \\
\text { general SNS functions out of } \\
\text { the desktop. }\end{array}$ & $\begin{array}{l}\text { Most family members lived } \\
\text { away from the elderly at the } \\
\text { time of the experiment. } \\
\text { Additional interviews with senior } \\
\text { citizens were conducted to } \\
\text { investigate subjective } \\
\text { responses, along with the } \\
\text { information collected from } \\
\text { Tlatoque, which was placed in } \\
\text { each household for a total of } \\
21 \text { weeks. }\end{array}$ & $\begin{array}{l}\text { Tlatoque was not only easy to } \\
\text { use but also facilitated the } \\
\text { integration of SNS and was } \\
\text { convenient to use in the } \\
\text { information exchange process. } \\
\text { All participants were positive and } \\
\text { enthusiastic about using } \\
\text { Tlatoque leading to enhanced } \\
\text { family interactions offline. }\end{array}$ & & $\bullet$ & $\bullet$ \\
\hline $\begin{array}{l}\text { Angelini et al., } \\
2015\end{array}$ & $\begin{array}{l}\text { Participants in the } \\
\text { demonstration event } \\
\text { for the prototype }\end{array}$ & $\begin{array}{l}\text { The study developed a } \\
\text { prototype of "Multisensory } \\
\text { Interactive Window" for the } \\
\text { elderly immersive experiences. } \\
\text { It supports family connection } \\
\text { and virtual tourism, and the } \\
\text { intuitive interface allows users } \\
\text { to interact with the target at } \\
\text { anytime and anywhere }\end{array}$ & $\begin{array}{l}\text { Through the opportunity to } \\
\text { experience the prototype, the } \\
\text { subjective opinion about the } \\
\text { Multisensory Interactive } \\
\text { Window, and the modification } \\
\text { and supplementation on the } \\
\text { way to output the 3D object, } \\
\text { environment, voice, and } \\
\text { fragrance were drawn }\end{array}$ & $\begin{array}{l}\text { Empirical assessment validate } \\
\text { the possibility of providing } \\
\text { realistic and vivid interactions } \\
\text { such as moving the camera to } \\
\text { the center of the screen and } \\
\text { creating a scent using an } \\
\text { ultrasound humidifier through } \\
\text { electrical plug control }\end{array}$ & & $\bullet$ & $\bullet$ \\
\hline
\end{tabular}

"•" means there is a connection between rows and columns.

experience of sunshine and sky proposed by Komorebi and CoeLux, a company for developing light systems. The startup company Rendever in the United States provides a step-bystep solution for education and recuperation of the elderly community, as well as a platform that allows users to experience a virtual natural environment. Maplewood Senior Living Center in the United States, which receives Rendever's services, is actively adopting VR/AR technology, including a creation of an immersive "Skylounge."

The AI/NLU technology can provides services to the elderly in everyday life and emergencies, based on natural language recognition for smooth communication and learning from the collected data. In a related case, Japan recently developed an animal-shaped robot as a solution to address the isolation and loneliness of the elderly; the robot provides user benefits such as communicating with animals and being comforted without having to look after a real pet (Banks et al., 2008). Paro, developed by the National Institute of Advanced Industrial Science and Technology (AIST) in Japan, is a seal-shaped robot that consists of four main senses: AI-based and NLU-based vision, hearing, balance, and touch. The assessment of the benefits of its use showed that the psychological status of the elderly was improved to a level similar to that of living with puppies (Wada and Shibata, 2007).

Other examples include Sony's Aibo and Omeron's NeCoRo, which have similar functions and purposes. In addition, KIA's Real-time Emotion Adaptive Driving (READ System), presented at the Consumer Electronics Show (CES) in 2019, could recognize the driver's vital signs and control the five senses in the vehicle to optimize the internal space of the vehicle considering a driver's emotions and situation in real time. In other words, current AI technology can adjust cameras and various sensors controlling music, temperature, lighting, and aroma based on user emotions and surrounding conditions. 
TABLE 5 | Product and services used in immersive experience technology.

\begin{tabular}{|c|c|c|c|}
\hline Technology & Service/product & Source & \\
\hline \multirow[t]{2}{*}{ VR } & $\begin{array}{l}\text { Step-by-step experience content for lifelong education and } \\
\text { rehabilitation }\end{array}$ & Ericsson-LG & https://www.ericsson.com/en/future-technologies \\
\hline & $\begin{array}{l}\text { VR/AR content for the elderly memories and natural recreation } \\
\text { experiences }\end{array}$ & Rendever & https://rendever.com/ \\
\hline VR/AR & Remotely controllable virtual olfactory device "VAQSO VR" & VAQSO & https://vaqso.com/ \\
\hline \multirow[t]{5}{*}{ AR } & AR projector lamp "Komorebi" to create virtual sunshine and shadows & LESLIE NOOTEBOOM & https://leibal.com/products/komorebi/ \\
\hline & Artificial light window that provides virtual sunlight and sky & Coelux & https://www.coelux.com/en/home-page/index \\
\hline & $\begin{array}{l}\text { Skype lounge to interact with friends and family through immersive } \\
\text { displays and audio }\end{array}$ & Maplewood Senior Living & https://www.maplewoodseniorliving.com/ \\
\hline & $\begin{array}{l}\text { AR indoor navigation app "Gatwick Airport Advertisement" at } \\
\text { London's Gatwick Airport }\end{array}$ & Gatwick Airport & https://www.gatwickairport.com/ \\
\hline & Qualcomm immersive Audio (3D sound) & Qualcomm & https://www.qualcomm.com/invention \\
\hline \multirow[t]{5}{*}{$\mathrm{Al} / \mathrm{NLU}$} & KIA Motors' Real-time Emotion Adaptive Driving (R.E.A.D. System) & Kia Media & https://www.kiamedia.com/ \\
\hline & Social robot PARO for communication and emotional care & AIST & http://www.parorobots.com/ \\
\hline & Al-based fall prediction and detection device & Kardian & http://kardian.com/ \\
\hline & $\begin{array}{l}\text { Social speaker NUGU providing natural language (speech) } \\
\text { recognizing daily life services }\end{array}$ & SKT & https://www.nugu.co.kr/ \\
\hline & $\begin{array}{l}\text { Al button MAGO, which provides services such as daily activities } \\
\text { services, dialogue and emergency treatment }\end{array}$ & MIKAWAYA21 & http://pr.mago-btn.com/ \\
\hline \multirow[t]{4}{*}{ HR } & Hologram table (Holoamp) & Holoamp & http://hololamp.tech/ \\
\hline & Hologram projector device & Studio joanie lemercier & https://joanielemercier.com/ \\
\hline & $\begin{array}{l}\text { "HealthVoyager" an immersive medical opinion system at Boston } \\
\text { Children's Hospital }\end{array}$ & HealthVoyager & https://www.healthvoyager.com \\
\hline & HoloLens for telemedicine and real-time communication & Microsoft & https://www.microsoft.com/en-us/hololens \\
\hline
\end{tabular}

Finally, HR technology is a major technology that can maximize visual immersion and create virtual objects that can interact with the physical environment in 3D (Buckley, 2011). Advances in screenless display technologies have led to the development of projector-based hologram tables and hologram projectors. The "HealthVoyager," an immersive medical observation system at Boston Children's Hospital, can provide medical care in 3D for young patients and caregivers. In addition, the HoloLens, developed by Microsoft, also provides $3 \mathrm{D}$ virtual objects that can interact with users in real time. Medical science is exploring how to use HoloLens to improve our understanding of telemedicine and care (Sirilak and Muneesawang, 2018). As such, the development and use of immersive experience technology suggest that environmental elements such as color, texture, and temperature/humidity can function as immersive tools. This makes it essential to be used to support our aging society.

\section{IMMERSIVE EXPERIENCE SERVICE MODEL IN THE ELDERLY WELFARE CENTER}

\section{Framework of Immersive Experience Service}

The immersive experience service is an ecosystem-based industry where contents, a service platform, network, and a device are all combined. The service requires an open platform to implement the related technologies. The service platform consists of components with individual functionalities, such as "input" to collect data, "process" to informationize and process the data, "store" to store the collected data and processing results to reuse them, and "output" to understand and share the characteristics of the results data. Figure 2 presents the framework of the immersive experience service proposed in this study.

The framework of the immersive experience service for successful aging informationizes the input data, synthesizes the processed result, and sends it to the device that realizes the service according to the program content, in order to support successful aging. The user can experience immersion via the provided service. Components and content of the immersive experience service platform for successful aging are as follows. The input data include biometric information, environmental information, user-specified information, and so forth. The data input from a user or an administrator, such as program information provided by a welfare facility or user-specific matter, is user-specified information. The input data are collected for the analysis or analyzed according to predefined principles and then visualized or natural language processed to produce a result. Each collected datum and result are archived for reuse and serviced through a connected output device.

\section{Immersive Experience Service Platform for Successful Aging}

Table 6 shows an immersive experience service platform for successful aging.

A total of 20 services were identified in this study. The input component data, according to each content item, are biometric 


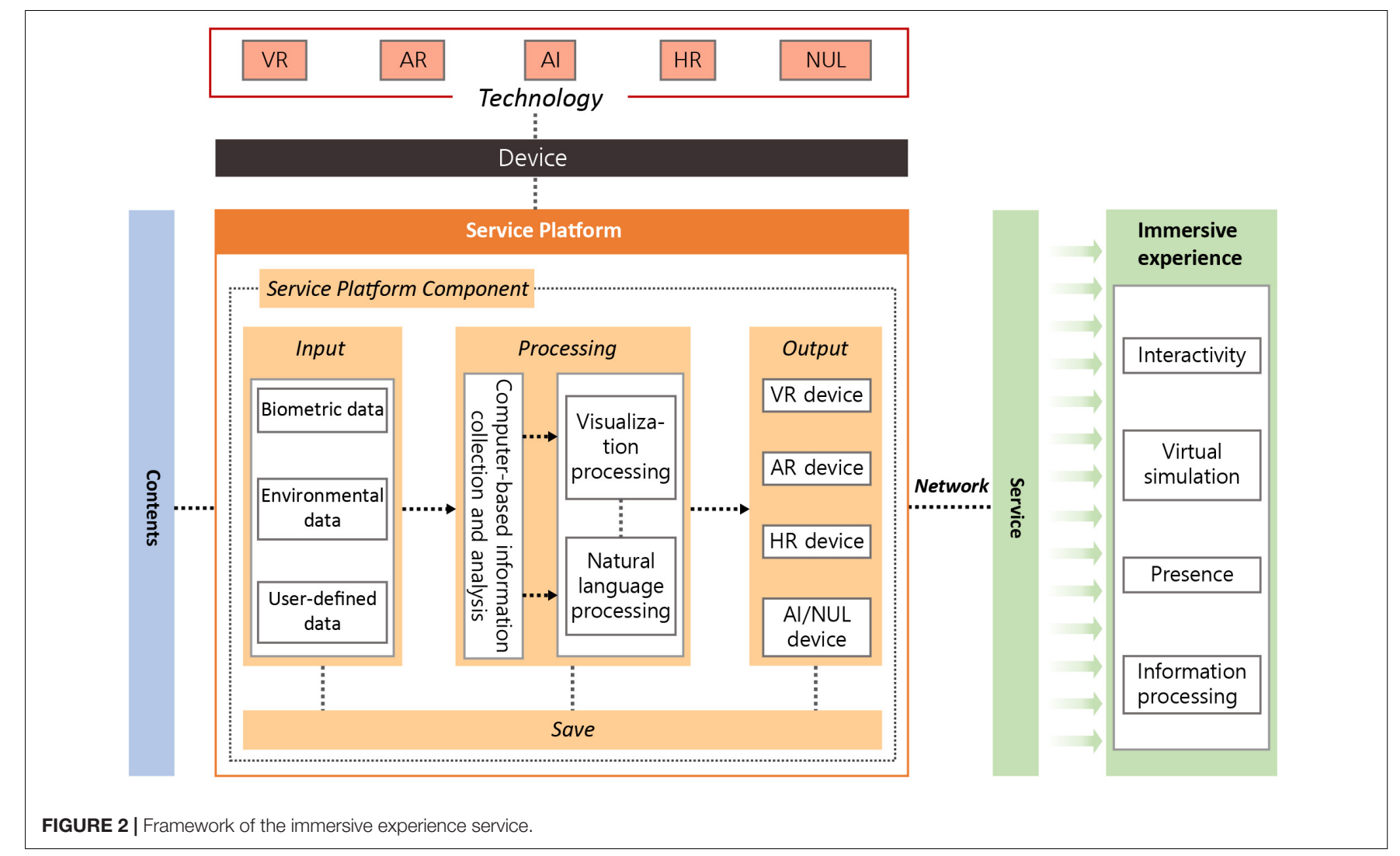

data, such as user health information and emotional state; environmental data, such as temperature/humidity, direction, light, and pressure information; and user-specified information, such as the support program and structure, elderly learning level, and parental contact information. In particular, as successful aging is a multidimensional and complex concept, it is important to continuously manage the knowledge of experts and facility personnel in each field such as individual counseling contents, physical and cognitive ability levels, and family relationships, in order to support various characteristics of elderly welfare center users. That is, it is important to provide a customized immersive service through real-time update and input of userspecified information. Information processing can be divided into two groups: VR/AR/HR graphic processing for visualizing analysis based on each data and AI/NLU program for recognizing and expressing natural language with a predetermined learning pattern. When the service is ready to deliver via each processing method, it can be outputted to the connected VR/AR/HR/AI/NUL device.

We presented psychologically immersive experience services as a series of examples. From the perspective of successful aging, it is important to support psychological traits to provide a controllable environment and qualities that remind us of good experiences and memories (Baltes and Baltes, 1990; Bhatt, 2015). To this end, the immersive experience service implements a VR graphic based on personal experiences or memories and can provide access to a virtual environment (e.g., a childhood home) through a VR device (S.10 and S.12). Furthermore, it can provide an immersive environment that allows interaction with virtual nature elements (sunlight, sky, animals, plants, etc.) and can be adjusted through AR lighting and HR projector through an intuitive AR/HR graphic process (S.8 and S.10). Finally, vocal and facial expression pattern information is analyzed by the AI and NLU programs to provide a customized indoor environment through the autonomous control device (S.11).

\section{Immersive Experience Service Model by Space of an Elderly Welfare Center}

Based on the derived immersive experience service, this study proposes an immersive experience service model by space of an elderly welfare center for successful aging, taking into account the functionality of an elderly welfare center. Table 7 shows an immersive experience service model based on an elderly welfare center.

Immersive experience content and services are provided through successful aging and functionality of the center. As mentioned above, these can be applied to up to 10 spaces in these centers. Additionally, a user can experience immersion such as presence, interactivity, virtual simulation, and information processing depending on a service provided. To apply this service in each space, the lobby and educational spaces need to support customized virtual experience activity for each program based on VR/AR technology. It is also important to create an immersive multimodal participation-based learning environment by sharing the results with the elderly in other communities. The physical 
TABLE 6 | Immersive experience service platform for successful aging.

\begin{tabular}{|c|c|c|c|c|c|}
\hline Successful aging & & Immersive experience service & Input & Processing & Output \\
\hline \multirow[t]{4}{*}{ Disease prevention } & S.1 & Remote virtual medical service & $\begin{array}{l}\text { User-definition, } \\
\text { Environment }\end{array}$ & HR graphic & $H R$ \\
\hline & S.2 & $\begin{array}{l}\text { Immersive medical note service based on the health } \\
\text { conditions }\end{array}$ & $\begin{array}{l}\text { User-definition, } \\
\text { Biometric }\end{array}$ & HR graphic & $\mathrm{HR}$ \\
\hline & S.3 & $\begin{array}{l}\text { Diet proposal and food information provision based on } \\
\text { the health condition }\end{array}$ & $\begin{array}{l}\text { Biometric, } \\
\text { User-definition }\end{array}$ & AR graphic & $A R$ \\
\hline & S.4 & $\begin{array}{l}\text { Identification of those at risk of falls and injuries, and } \\
\text { undertaking preventive measures by learning various } \\
\text { postures }\end{array}$ & $\begin{array}{l}\text { Biometric, } \\
\text { Environment, } \\
\text { User-definition }\end{array}$ & $\begin{array}{l}\text { Al program, } \\
\text { NLU program }\end{array}$ & $\mathrm{Al}, \mathrm{NLU}$ \\
\hline \multirow[t]{3}{*}{$\begin{array}{l}\text { Physical and recognitive } \\
\text { functionality }\end{array}$} & S.5 & Step-by-step Al-based virtual training contents & $\begin{array}{l}\text { Biometric, } \\
\text { User-definition }\end{array}$ & VR graphic & VR \\
\hline & S.6 & $\begin{array}{l}\text { Step-by-step virtual training contents based on the } \\
\text { physical capability }\end{array}$ & $\begin{array}{l}\text { Biometric, } \\
\text { User-definition }\end{array}$ & VR graphic & VR \\
\hline & S.7 & $\begin{array}{l}\text { Real-time route detection and AR navigation service } \\
\text { based on the program }\end{array}$ & $\begin{array}{l}\text { User-definition, } \\
\text { Environment }\end{array}$ & AR graphic & $A R$ \\
\hline \multirow[t]{5}{*}{$\begin{array}{l}\text { Psychological } \\
\text { characteristics }\end{array}$} & S.8 & $\begin{array}{l}\text { Providing scattering of light, sunshine, and virtual sky } \\
\text { through illumination }\end{array}$ & User-definition & AR graphic & $\mathrm{AR}$ \\
\hline & S.9 & $\begin{array}{l}\text { Virtual travel contents for natural resorts or tourist } \\
\text { attractions }\end{array}$ & User-definition & VR graphic & VR \\
\hline & S.10 & $\begin{array}{l}\text { Virtual nature environment factor (indoor garden, } \\
\text { aquarium, etc.) service in space }\end{array}$ & User-definition & $\begin{array}{l}\text { AR graphic, } \\
\text { HR graphic }\end{array}$ & $\mathrm{AR}, \mathrm{HR}$ \\
\hline & S.11 & $\begin{array}{l}\text { Customized indoor environment (lighting, sunlight, } \\
\text { sound, etc.) service based on the physical/emotional } \\
\text { status }\end{array}$ & $\begin{array}{l}\text { Biometric, } \\
\text { Environment, } \\
\text { User-definition }\end{array}$ & $\begin{array}{l}\text { Al program, } \\
\text { NLU program }\end{array}$ & $\mathrm{Al}$ \\
\hline & S.12 & $\begin{array}{l}\text { Virtual memory remembrance contents based on the } \\
\text { experience }\end{array}$ & User-definition & VR graphic & VR \\
\hline \multirow[t]{4}{*}{ Productive activity } & S.13 & $\begin{array}{l}\text { Customized job information service through analyzing } \\
\text { data on training and learning }\end{array}$ & User-definition & $\begin{array}{l}\text { Al program, } \\
\text { NLU program }\end{array}$ & $\mathrm{Al}$ \\
\hline & S.14 & Virtual job experience and education contents & User-definition & VR graphic & VR \\
\hline & S.15 & $\begin{array}{l}\text { Customized virtual environment contents associated } \\
\text { with hobbies/education programs }\end{array}$ & User-definition & $\begin{array}{l}\text { VR graphic, } \\
\text { AR graphic }\end{array}$ & $\mathrm{VR}, \mathrm{AR}$ \\
\hline & S.16 & $\begin{array}{l}\text { Sharing hobbies and education outcomes with the } \\
\text { elderly from other regional communities }\end{array}$ & $\begin{array}{l}\text { User-definition, } \\
\text { Environment }\end{array}$ & $\begin{array}{l}\text { AR graphic, } \\
\text { HR graphic }\end{array}$ & $\mathrm{AR}, \mathrm{HR}$ \\
\hline \multirow[t]{4}{*}{ Social interaction } & S.17 & Realistic 3D virtual object (bird, dolphin, etc.) service & $\begin{array}{l}\text { User-definition, } \\
\text { Environment }\end{array}$ & HR graphic & $\mathrm{HR}$ \\
\hline & S.18 & $\begin{array}{l}\text { Social robot service that recognizes and expresses } \\
\text { natural language }\end{array}$ & $\begin{array}{l}\text { Biometric, } \\
\text { User-definition }\end{array}$ & $\begin{array}{l}\text { Al program, } \\
\text { NLU program }\end{array}$ & $\mathrm{Al}, \mathrm{NLU}$ \\
\hline & S.19 & $\begin{array}{l}\text { Immersive space service that allows to remotely } \\
\text { communicate with friends and family }\end{array}$ & $\begin{array}{l}\text { Environment, } \\
\text { User-definition }\end{array}$ & $\begin{array}{l}\text { AR graphic, } \\
\text { HR graphic }\end{array}$ & $\mathrm{AR}, \mathrm{HR}$ \\
\hline & S.20 & $\begin{array}{l}\text { Multimodal participation virtual environment and game } \\
\text { contents based on social VR }\end{array}$ & User-definition & VR graphic & VR \\
\hline
\end{tabular}

activity space should support enjoying the virtual activities together with the other elderly by using social VR. In an autonomous space, such as a fitness room, it is necessary to learn the behavioral patterns for fall and have virtual coaches for exercise equipment. In a medical space, remote treatment through a hologram is needed due to the absence of a specialist, and a medical note service is provided using a virtual object to help understand more about the health condition. The rehabilitation space needs to provide an autonomous environment adjustment, such as providing and recovering VR content step by step, in order to improve cognition and physical function, and light and temperature/humidity according to the emotional state. In the counseling and employment space, individual counseling and employment support should be provided based on the learning ability and aptitude of the elderly, and it will be important to build confidence in job activities following retirement, through virtual job experience. The elderly welfare centers providing lunch should develop a method to provide information in an easy way using an AR application, such as analyzing the health conditions and diet-related information of an elderly person to provide customized meals and health-related information through food photos.

The resting area is a center of immersive experience that can provide up to nine services. It can provide a dynamic nature immersion environment, such as a virtual sky, sunlight, HR/AR, and natural creatures (plants, birds, dolphins, and so forth), for psychological well-being and relaxation. Lastly, the public space in these centers is a space where exchange and movement occur. As the elderly welfare center program is conducted in different places 
TABLE 7 | Immersive experience service model according to the elderly welfare center.

\begin{tabular}{|c|c|c|c|c|c|c|c|c|c|c|c|c|c|}
\hline \multirow[t]{3}{*}{ Contents } & \multirow[t]{3}{*}{ Technology } & \multirow[t]{3}{*}{ Service } & \multicolumn{10}{|c|}{ Function and spaces } & \multirow[t]{3}{*}{$\begin{array}{l}\text { Characteristic Immersive } \\
\text { experience }\end{array}$} \\
\hline & & & \multicolumn{3}{|c|}{ Leisure and education } & \multicolumn{2}{|c|}{ Function recovery } & \multicolumn{2}{|c|}{ Counseling and employment } & \multicolumn{3}{|c|}{ Promoting exchange } & \\
\hline & & & $\begin{array}{c}\text { Hobbies } \\
\text { activity }\end{array}$ & Education & $\begin{array}{r}\text { Physical } \\
\text { activity }\end{array}$ & $\begin{array}{l}\text { Medical } \\
\text { care }\end{array}$ & Rehabilitation & Counseling & Employment & Refection & Rest & $\begin{array}{c}\text { Communal } \\
\text { space }\end{array}$ & \\
\hline \multirow[t]{2}{*}{ Medical treatment } & $\mathrm{HR}$ & S.1 & & & & O & & & & & & & Presence \\
\hline & $\mathrm{HR}$ & S.2 & & & & $\mathrm{O}$ & & & & & & & Presence \\
\hline Health information & $\mathrm{Al} / \mathrm{AR}$ & S.3 & & & & & & & & $\mathrm{O}$ & & & Information processing, Interactivity \\
\hline Prevention of falling & $\mathrm{Al} / \mathrm{NLU}$ & S.4 & & & $\mathrm{O}$ & & $\mathrm{O}$ & & & & & & Information processing \\
\hline Cognitive training & VR & S.5 & & & & & $\mathrm{O}$ & & & & & & Interactivity, Virtual simulation \\
\hline Physical training & VR & S.6 & & & O & & & & & & & & Interactivity, Virtual simulation \\
\hline Navigation & $\mathrm{AR}$ & S.7 & $\mathrm{O}$ & $\mathrm{O}$ & $\mathrm{O}$ & $\mathrm{O}$ & $\mathrm{O}$ & $\mathrm{O}$ & O & $\mathrm{O}$ & $\mathrm{O}$ & $\mathrm{O}$ & Interactivity \\
\hline \multirow[t]{3}{*}{ Natural healing } & $\mathrm{AR}$ & S.8 & O & $\mathrm{O}$ & O & $\mathrm{O}$ & $\mathrm{O}$ & $\mathrm{O}$ & 0 & O & $\mathrm{O}$ & $\mathrm{O}$ & Virtual simulation \\
\hline & VR & S.9 & O & & & & & & & & $\mathrm{O}$ & & Virtual simulation \\
\hline & $\mathrm{AR} / \mathrm{HR}$ & S.10 & & & & & & & & & O & $\mathrm{O}$ & Presence \\
\hline Mental stability & $\mathrm{Al} / \mathrm{NLU}$ & S.11 & & & & $\mathrm{O}$ & $\mathrm{O}$ & $\mathrm{O}$ & & & $\mathrm{O}$ & & Information processing \\
\hline Recollection of memories & VR & S.12 & & & & & & & & & $\mathrm{O}$ & & Virtual simulation \\
\hline Employment information & $\mathrm{Al}$ & S.13 & & & & & & & $\mathrm{O}$ & & & & Information processing \\
\hline \multirow[t]{3}{*}{ Hobbies and education } & VR & S.14 & & & & & & & O & & & & Virtual simulation \\
\hline & $\mathrm{VR} / \mathrm{AR}$ & S.15 & $\mathrm{O}$ & $\mathrm{O}$ & & & & & & & & & Virtual simulation \\
\hline & $\mathrm{AR} / \mathrm{HR}$ & S.16 & $\mathrm{O}$ & $\mathrm{O}$ & & & & & & & & & Interactivity, Presence \\
\hline Communion with nature & $\mathrm{HR}$ & S.17 & & & & & & & & $\mathrm{O}$ & $\mathrm{O}$ & $\mathrm{O}$ & Presence \\
\hline \multirow[t]{3}{*}{ Communication } & $\mathrm{Al} / \mathrm{NLU}$ & S.18 & & & & & & & & O & O & $\mathrm{O}$ & Information processing, Interactivity \\
\hline & $\mathrm{AR} / \mathrm{HR}$ & S.19 & & & & & & & & & $\mathrm{O}$ & & Presence \\
\hline & VR & S.20 & & & 0 & & & & & & & & Virtual simulation, interactivity \\
\hline
\end{tabular}

"O" means there is a connection between rows and columns. 
depending on the individual timetables, it will be important to support navigation by providing an AR navigation tool that can guide the route in real time. In addition, an AI social robot that recognizes and expresses natural language can be used as a primary means of communication and provision of information.

\section{DISCUSSION}

This study proposed the immersive experience service model through linkage with immersion technology, considering the function and space composition of the elderly welfare center for the successful aging of the elderly. The architectural field has emphasized the improvement of physical environment or physical support focused on an evidence-based design, a universal design, and a barrier-free design. The purpose of this study was to explore the elderly welfare center environment from a new perspective by linking immersive experience skills that improve life satisfaction and social interaction, as a way to support mental and social functions important in successful aging. In addition, the immersive experience service discussed in this study can alleviate the physical and spatial constraints of the elderly and can function positively in successful aging by providing immersion into the desired environment and situation. Thus, it has sufficient value to support its application in the elderly welfare centers. The results of this study are summarized as follows.

First, successful aging is a process of actively coping with deterioration and impairment of old age, and can be defined as disease prevention, high level of physical and cognitive function, psychological stability, productive activity, and social relationships. Therefore, it is necessary to prepare support measures for successful aging in a comprehensive manner through linkage with local communities and by applying technology to efficiently provide this. In particular, the elderly welfare centers, as facilities used for the leisure and education of the elderly, recovery of skills, counseling and employment, and social interaction, must compose programs and provide relevant services to support successful aging. In this study, we analyzed the spatial composition of the elderly welfare centers by function to support successful aging by classifying these into hobbies, physical activity, education, medical, rehabilitation, counseling, employment information, refection, rest, and common spaces.

Second, the analysis of the previous studies shows that the effects of the immersion experience skills of the elderly are improved through improved physical balance and fatigue levels (Lai et al., 2013; Wu et al., 2013; Calogiuri et al., 2018), attention and memory (Zelinski and Reyes, 2009), and reduced depression, improved social skills, and stress reduction ( $\mathrm{Wu}$ et al., 2013). This study derived the main technologies supporting the immersive experience of the elderly. These included VR, AR, AI, NLU, and HR. The immersive experience should be provided with the contents according to the functions of the user and the space as the main technologies are combined. Based on the results of our review examining the product and service trends of immersive experience technology, VR and AR technology include natural immersion product development, virtual training and rehabilitation content, and a path-finding application that induces a positive experience with nature. In this case, there are AI social robots for reducing the depression of elderly people through emotion recognition of facial expression and biosignal analysis and an autonomous control system for natural language communication. HR technology is developing products such as projectors and wearable devices to implement holograms, and medical finding systems and telemedicine are being increasingly used.

Third, the immersive experience service consists of content, platform, network, and device, and the service platform includes components of input, processing, storage, and output functions. This study constructed an immersive experience service platform for successful aging, with the input variables including biological information, environmental information, and personal information of elderly people. Processing collects and analyzes information about the input data and then visualizes or uses natural language processing to produce the result. The storage maintains the generated results for reuse, with the output being a device that presents the generated results to the outside world. The elderly are provided with the immersive experiences of presence, interactivity, virtual simulation, and information processing characteristics depending on the elderly welfare center's available space and programs.

Finally, we derived 20 service content items considering the goals of successful aging and functions of the elderly welfare centers. We also suggested an immersive experience service model based on the functionally classified space of the elderly welfare center. The service content for each space is as follows. The hobbies and educational spaces support virtual experience activities according to the program and provide a multiparticipatory learning environment that shares the results with the elderly of other communities. In the physical activity space, virtual activities for each group should be performed according to the level of physical function, and in the case of an autonomous activity space without a monitor, a fall prediction system and a hologram virtual coach will be required for the safety of the elderly. As medical spaces in the centers are not manned, it will be important to support a good flow of communication with the elderly, such as delivering medical results using virtual objects during remote medical care and providing medical treatment using holograms such as HoloLens. Rehabilitation spaces need to support step-by-step learning content for cognitive and physical function training and provide a customized environment based on the physical and emotional states of the elderly. The counseling and employment space will provide consultation and employment information by analyzing the elderly learning data and aptitudes, as well as providing virtual job experiences and virtual education. Food and beverage spaces will need to provide food based on individual diets and other food-related information using AR applications, and rest spaces could support psychological well-being through the interaction with animals and plants using a virtual natural environment. Finally, public spaces could provide a real-time route search and an AR navigation according to the individual program timetables and also provide information on facilities for 
the elderly welfare centers and support natural communication using social AI robots.

\section{CONCLUSION}

This study sought to apply immersive experience technology to the successful aging of the elderly. The immersive experience service was derived by linking the survey contents with the recently released immersive technology. The service of the elderly welfare centers for successful aging was presented as 20 applications methods by space, according to the functional classification of the elderly welfare centers. The study proposed the use of an immersive experience service system based on the characteristics of the immersive experience, according to service content. This study is a novel Contribution To The Field of elderly friendly architecture and construction. By subdividing the immersive experience service system according to the services provided by the existing elderly welfare centers, this study contributes to the improvement of applicability of the immersive experience service system to the real-life elderly welfare centers. Finally, this study provides a direction in which to expand the application of immersive experience technology and services for the elderly, including the entertainment, education, and medical fields. However, it should be noted that the immersive experience service model proposed in this study deals with the current program content and is limited to the currently developed technology. A further study is required to analyze the existing quantitative data in a clear and rigorous manner (including conducting in-depth interviews with the users) and to broaden the scope of the search criteria to alleviate the limitations on the

\section{REFERENCES}

Angelini, L., Caon, M., Couture, N., Khaled, O. A., and Mugellini, E. (2015). "The multisensory interactive window: immersive experiences for the elderly," in : Adjunct Proceedings of the 2015 ACM International Joint Conference on Pervasive and Ubiquitous Computing and Proceedings of the 2015 ACM International Symposium on Wearable Computers (New York, NY: ACM), 963-968.

Anguera, J. A., Boccanfuso, J., Rintoul, J. L., Al-Hashimi, O., Faraji, F., Janowich, J., et al. (2013). Video game training enhances cognitive control in older adults. Nature 501:97. doi: 10.1038/nature12486

Baltes, P. B., and Baltes, M. M. (1990). "Psychological perspectives on successful aging: the model of selective optimization with compensation," in Successful aging: Perspectives from the behavioral sciences, eds P. B. Baltes, \& M. M. Balte (Cambridge: Cambridge University Press), 1-34. doi: 10.1017/ cbo9780511665684.003

Banks, M. R., Willoughby, L. M., and Banks, W. A. (2008). Animal-assisted therapy and loneliness in nursing homes: use of robotic versus living dogs. J. Am. Med. Dir. Assoc. 9, 173-177. doi: 10.1016/j.jamda.2007.11.007

Bhatt, H. (2015). Biophilic Design for the Elderly: Design of a Senior Living Community Along the Delaware. Thesis.Philadelphia University, Philadelphia.

Buckley, E. (2011). Holographic laser projection. J. Disp. Technol. 7, 135-140. doi: 10.1109/JDT.2010.2048302

Calogiuri, G., Litleskare, S., Fagerheim, K. A., Rydgren, T. L., Brambilla, E., and Thurston, M. (2018). Experiencing nature through immersive virtual environments: environmental perceptions, physical engagement, and affective responses during a simulated nature walk. Front. Psychol. 8:2321. doi: 10.3389/ fpsyg.2017.02321 use of immersion technology for the elderly. The ultimate goal of this study is to apply immersion technology that can interact with programs for each space in the physical environment, such as at the elderly welfare centers, assuming that the experience of immersion and the characteristics of the technology can function positively toward successful aging. This can be of value for the development of the elderly welfare centers.

\section{DATA AVAILABILITY STATEMENT}

All datasets generated for this study are included in the article/supplementary material.

\section{AUTHOR CONTRIBUTIONS}

EL and SP conceived and designed the research. EL collected and analyzed the information by reviewing the literature and investigating the case, and providing a substantial contribution to writing of the manuscript. SP provided the insights about the outline in the process of research progress, and also consistently examined, modified, and supplement the manuscript. Both authors interpreted the results and the meaning of the research, and approved the final manuscript.

\section{FUNDING}

This study was funded by the Korea Research Foundation grant. Project number: NRF $=$ 2018R1C1B6008735.

Chodzko-Zajko, W., Schwingel, A., and Park, C. H. (2009). Successful aging: the role of physical activity. Am. J. Lifestyle Med. 3, 20-28. doi: 10.1177/ 1559827608325456

Cornejo, R., Tentori, M., and Favela, J. (2013). Enriching in-person encounters through social media: a study on family connectedness for the elderly. Int. J. Hum-Comput. St. 71, 889-899. doi: 10.1016/j.ijhcs.2013.04.001

Cummings, J. J., and Bailenson, J. N. (2016). How immersive is enough? A metaanalysis of the effect of immersive technology on user presence. Media Psychol. 19, 272-309. doi: 10.1080/15213269.2015.1015740

Duay, D. L., and Bryan, V. C. (2006). Senior adults' perceptions of successful aging. Educ. Gerontol. 32, 423-445. doi: 10.1080/03601270600685636

Gallistl, V. (2018). The emergence of the creative ager-On subject cultures of late-life creativity. J. Aging Stud. 46, 93-99. doi: 10.1016/j.jaging.2018.07.002

Havighurst, R. J. (1963). Successful aging. Proc. Aging: Soc. Psychol. Perspect. 1, 299-320.

Hayflick, L. (2000). The future of ageing. Nature. 408:267. doi: 10.1038/35041709

Hong, D. H., and Yoo, J. W. (2017). A study on the characteristics of seniors welfare center as a leisure activity space for the elderly -concentrated on seniors welfare center of Changwon city. JAIK PD. 19, 61-72. doi: 10.6564/JKMRS.2015.19. 2.061

Jeong, H. K. (2019). "The experience of immersion, to what extent has it been realized?", in Smart Device Trend Magazine (Korea: IITP).

Keshner, E. A., and Kenyon, R. V. (2004). Using immersive technology for postural research and rehabilitation. Assist. Technol. 16, 54-62. doi: 10.1080/10400435. 2004.10132074

Kim, W. J., Lee, T. K., and Yang, S. Y. (2017). A study on senior welfare center color environment according to space function -focus on Busan city-. J. Korean Hous. Assoc. 28, 98-108. doi: 10.6107/JKHA.2017.28.4.095 
Lai, C.-H., Peng, C.-W., Chen, Y.-L., Huang, C.-P., Hsiao, Y.-L., and Chen, S.C. (2013). Effects of interactive video-game based system exercise on the balance of the elderly. Gait P. 37, 511-515. doi: 10.1016/j.gaitpost.2012. 09.003

Lera, F. J., Rodríguez, V., Rodríguez, C., and Matellán, V. (2014). “Augmented reality in robotic assistance for the elderly," in International Technology Robotics Applications, ed L. G. Alonso (Berlin: Springer), 3-11. doi: 10.1007/978-3-31902332-8_1

Libin, A., and Cohen-Mansfield, J. (2004). Therapeutic robocat for nursing home residents with dementia: preliminary inquiry. Am. J. Alzheimer's Dis Other Dement. 19, 111-116. doi: 10.1177/153331750401900209

Lim, H. S., Go, D. G., and Park, S. C. (2014). The problems and methods for improvement on the operation of welfare facilities for the leisure time of the elderly: analysis on the cases for the 528 welfare facilities for the leisure time of the elderly. JWCE 3, 81-100.

Ministry of Health and Welfare (2019). Current Status of Welfare Facilities for the Elderly in 2019. Available at: https://hoy.kr/8PpFs (accessed August, 2019).

Nusselder, W. J., and Peeters, A. (2006). Successful aging: measuring the years lived with functional loss. J. Epidemiol. Community Health 60, 448-455. doi: 10.1136/jech.2005.041558

OECD, (2005). Ageing and Employment Policies. Paris: OECD.

Ouwehand, C., de Ridder, D. T., and Bensing, J. M. (2007). A review of successful aging models: Proposing proactive coping as an important additional strategy. Clin. Psychol. Rev. 27, 873-884. doi: 10.1016/j.cpr.2006.11.003

Park, S. J., Lee, H., and Kim, M. J. (2013). Mixed-Use Facility Model for the Welfare of the Elderly Based on Lifestyle. J. Asian Archit. Build. 12, 245-252. doi: $10.3130 /$ jaabe. 12.245

Rowe, J. W., and Kahn, R. L. (1998). Successful aging: The MacArthur Foundation Study. New York, NY: Pantheon.

Rowe, J. W., and Kahn, R. L. (2015). Successful aging 2.0: conceptual expansions for the 21st century. J. Gerontol. B. 70, 593-596. doi: 10.1093/geronb/gbv025

Sauter, P. M. (2003). VR $2 \mathrm{Go}^{\mathrm{TM}}$ : a new method for virtual reality development. Comput. Graph. -N. Y. Assoc. Comput. Mach. 37, 19-24.

Shin, Y. (2016). A study on application of the elements of healing design according to functional space of senior activity centers- with a focus on the effects of color and image of nature on a sense of comfort. J. Integr. Des. Res. 15, 123-136. doi: $10.21195 /$ jidr.2016.15.2.011

Sirilak, S., and Muneesawang, P. (2018). A New Procedure for Advancing Telemedicine Using the HoloLens. IEEE Access. 6, 60224-60233. doi: 10.1109/ ACCESS.2018.2875558

Statistics Korea. (2018). Result of the 2017 Total Survey on Population and Housing. Available at: https://hoy.kr/KWmRT (accessed July, 2019).
Vaillant, G. E. (2008). Aging Well: Surprising Guideposts to a Happier life From the Landmark Study of Adult Development. Boston, MA: Little, Brown.

Vasunilashorn, S., Steinman, B. A., Liebig, P. S., and Pynoos, J. (2012). Aging in place: evolution of a research topic whose time has come. J. Aging Res 2012:120952. doi: 10.1155/2012/120952

Wada, K., and Shibata, T. (2006). "Living with seal robots in a care house-evaluations of social and physiological influences," in 2006 IEEE/RSJ International Conference on Intelligent Robots and Systems (Piscataway, NJ: IEEE), 4940-4945.

Wada, K., and Shibata, T. (2007). Living with seal robots-its sociopsychological and physiological influences on the elderly at a care house. IEEE T. Robot. 23, 972-980. doi: 10.1109/TRO.2007.906261

Whitlock, L. A., McLaughlin, A. C., and Allaire, J. C. (2012). Individual differences in response to cognitive training: Using a multi-modal, attentionally demanding game-based intervention for older adults. Comput. Hum. Behav. 28, 1091-1096. doi: 10.1016/j.chb.2012.01.012

Wiemeyer, J., and Kliem, A. (2012). Serious games in prevention and rehabilitation-a new panacea for elderly people? EURAPA. 9:41. doi: 10.1007/ s11556-011-0093-x

Wollersheim, D., Merkes, M., Shields, N., Liamputtong, P., Wallis, L., Reynolds, F., et al. (2010). Physical and psychosocial effects of Wii video game use among older women. Int. J. Emerg. Technol. Soc. 8, 85-98.

Wu, Y.-H., Wrobel, J., Cristancho-Lacroix, V., Kamali, L., Chetouani, M., Duhaut, D., et al. (2013). Designing an assistive robot for older adults: the ROBADOM project. IRBM. 34, 119-123. doi: 10.1016/j.irbm.2013.01.003

Yamagami, T., Oosawa, M., Ito, S., and Yamaguchi, H. (2007). Effect of activity reminiscence therapy as brain-activating rehabilitation for elderly people with and without dementia. Psychogeriatrics. 7, 69-75. doi: 10.1111/j.1479-8301. 2007.00189.x

Zelinski, E. M., and Reyes, R. (2009). Cognitive benefits of computer games for older adults. Gerontechnology. 8:220. doi: 10.4017/gt.2009.08.04.004.00

Conflict of Interest: The authors declare that the research was conducted in the absence of any commercial or financial relationships that could be construed as a potential conflict of interest.

Copyright $(2020$ Lee and Park. This is an open-access article distributed under the terms of the Creative Commons Attribution License (CC BY). The use, distribution or reproduction in other forums is permitted, provided the original author(s) and the copyright owner(s) are credited and that the original publication in this journal is cited, in accordance with accepted academic practice. No use, distribution or reproduction is permitted which does not comply with these terms. 